\title{
Study on the Evaluation of Green Food Export Development Efficiency in Heilongjiang Province
}

\author{
Li Zhao \\ Harbin University of Commerce, Harbin 150028, China \\ Zhaoli0515@163.com
}

Keywords: Green food; export efficiency; DEA model; industrial development mode transformation

\begin{abstract}
The expansion of the industrial scale reflects the development level of the industry to a certain extent, and plays an important supporting role in promoting the sustainable development of the industry and the enhancement of industrial competitiveness. Compared with the expansion of industrial scale, the performance of export development of green food industry in Heilongjiang Province is not significant. Therefore, it is an important prerequisite to analyze and evaluate the development efficiency of green food export in Heilongjiang Province scientifically that is to formulate industrial export development policies. This paper uses the $\mathrm{C} 2 \mathrm{R}$ model to analyze the export development efficiency characteristics and scale returns of green foods empirically in Heilongjiang Province from 2001 to 2014. The results show that the overall efficiency of green food export development in Heilongjiang Province is low and declining. The resource potential has not been fully tapped, resource allocation has not reached the optimal state, and industrial development has shown a "scale uneconomic" trend. According to the analysis results, it is proposed to promote the transformation of industrial development mode to intensive, outward-oriented and efficiencyoriented, optimize the export efficiency through the optimization and upgrading of input factor structure, and play the role of export-oriented policy guidance and "reverse pull" to promote the sustainable development of green food export in Hei Longjiang Province.
\end{abstract}

\section{Introduction}

The development of green foods is of great significance which to adjust the structure of agricultural industries, change traditional agricultural production methods, and lead the optimization and upgrading of consumption structure. As an important part of the complete green food system, the green food planting, aquaculture and processing industries in Heilongjiang Province have developed rapidly in recent years, and the industrial scale effect and regional comparative advantages have gradually emerged. In 2015, the physical output of green food in Heilongjiang Province reached 38 million tons, and the monitoring area reached 72.09 million mu, both hitting record highs and the industry showed a good growth trend. In the process of rapid expansion of the green food industry in Heilongjiang Province, the scale of export development is small and the growth rate is slow. Especially in recent years, exports have shown significant fluctuations, export growth performance is not significant, and the development foundation of the green food industry and the formation of production status formed a great contrast. If the export of green food can not play a leading and leading role, it will restrict the optimization of product structure, affect the performance of industrial development, and even hinder the competitiveness of green food export in Heilongjiang Province and the sustainable and coordinated development of green food industry. Therefore, it is necessary that how to crack the "bottleneck" in the development of green food exports, promote the growth of export scale, increase the efficiency, and promote the competitiveness of Heilongjiang green food brands and the further development of exports.

This paper evaluates the dynamic change process of green food export development efficiency in Heilongjiang Province by establishing the CR model of DEA method, determines the main factors affecting industrial efficiency change and points out the improvement direction. By analyzing the 
industrial scale income status, it points out the impact which scale efficiency to the overall efficiency of industrial development. It is of great significance to formulate the strategy for the development of green food exports in Heilongjiang Province, improve the efficiency of the green food industry in Heilongjiang Province and promote the development of green food exports.

\section{Method selection and model building}

Green food exports, as an important component of the green food industry development system, are influenced and constrained by various elements within the green food industry development system. The development of green food exports is the embodiment of industrial development in terms of exports and the result and driving force of industrial development. Considering the complex relationship between the variables of the green food export status, it is difficult to use the deterministic function to express the expression. The dimension and weight are different.. The DEA method is suitable for the input data of the input, and can be used for the decision-making unit from the perspective of investment output and conducted relative efficiency analysis and evaluation to effectively avoid non-objectivity of evaluation.

Establish a green food export development efficiency evaluation model, first assume that the green food exports' $n$ DMU, and each DMU has $m$ kinds of input and $s$ kinds of output, the $j$ th DMU input and output vectors of the green food export system represented by $x_{j}=\left(x_{1 j}, x_{2 j}, \ldots x_{m j}\right)^{T}$ and $Y_{J}=\left(y_{1 j}, y_{2 j}, \ldots y_{s j}\right)^{T}\left(x_{i j}>0, y_{i j}>0 \quad j=1,2, . . n\right)$ respectively, Second, the $C^{2} R$ model for evaluating the relative effectiveness of green food export development is:

$$
\min =\left[\theta-\varepsilon\left(\sum_{i=1}^{m} S_{i}^{-}+\sum_{r=1}^{s} S_{r}^{+}\right)\right] \text {s.t. }\left\{\begin{array}{l}
\sum_{j=1}^{n} \boldsymbol{X}_{j} \lambda_{j}+\boldsymbol{S}^{-}=\boldsymbol{O} \boldsymbol{X}_{\mathrm{o}} \\
\sum_{j=1}^{n} \boldsymbol{Y}_{j} \lambda_{j}-\boldsymbol{S}^{+}=\boldsymbol{Y}_{\mathrm{O}} \\
\lambda_{j} \geq \mathbf{O}, \boldsymbol{S}^{-}, \boldsymbol{S}^{+} \geq \mathbf{O}
\end{array}\right.
$$

Among them, $\theta$ is the green food export development ability index of each period, $m$ and $s$ represent the number of input and output variables in the green food export system respectively; ${ }^{-}$; and $S_{r}^{+}$represent the respective slack variables corresponding to inputs and outputs, respectively, $n$ represents the number of DMUs of the same type; $x_{i j o}$ and $y_{i j o}$ represent the i-th input and the r-th output variable of the jth DMU respectively; $\varepsilon$ represents non-Archimedean infinitesimal, often the value is $\varepsilon=10^{-5}$.

The economic significance of constructing the $C^{2} R$ model is that by looking for some linear combination of $n$ DMUs, the investment is as low as possible under the condition that its output is not lower than the output of the ${ }^{j_{0}}$ th DMU. If the obtained optimal value of the green food export development index $\theta$ is less than 1 , it means that fewer input factors can be found to obtain no less than the decision unit of the evaluated DMU output, indicating that the DMU is invalid for DEA; When the green food export development index $\theta=1$, it indicates that the DMU is valid for DEA. The model is constructed from the perspective of constant output and reduced investment, so it is called the efficiency evaluation model of input.

\section{DEA empirical analysis}

\subsection{Decision unit selection and variable selection}

In this paper, the green food industry in Heilongjiang Province was divided into 14 periods from 2001 to 2014. The time-point level of industrial development in 14 periods was used as the decision-making unit DMU to analyze the export efficiency characteristics of green food exports in Heilongjiang Province at various points in time.

China's green food industry is defined by the number of green food enterprises and the number of products. The monitoring area of production area is an important input factor for the green food 
industry, which directly determines the output and export of the green food industry. Green food production and sales are the physical form and value standard for measuring industrial development. Therefore, the number of enterprises, the number of products and the monitoring area of production, physical output and annual sales are selected as input indicators. Due to the variety of green foods and the different dimensions of physical products, this paper does not choose the export volume of green food, but chooses the export value as the output index.

\subsection{Data Sources}

The input and output data of green (organic) food industry and export development in Heilongjiang Province from 2001 to 2014 comes from the "Green Food Statistics Annual Report" (2002-2015), "Heilongjiang Statistical Yearbook" (2002-2015) and Heilongjiang Agricultural Information.

\subsection{Empirical analysis}

Using Coelli's (1996) Deap2.1 analysis software, the $C^{2} R$ model was used to measure the comprehensive efficiency, pure technical efficiency and scale efficiency of the development of green food exports in Heilongjiang Province. The results are shown in Table 1.

It can be seen from Table 1 that the development of green food exports in Heilongjiang Province is obviously ineffective, and the scale expansion of the industry is not in harmony with the development of exports. Analysis as follows:

Table1. Evaluation results of green food export development efficiency in Heilongjiang Province from 2001 to 2014

\begin{tabular}{|c|c|c|c|c|c|c|c|c|}
\hline \multirow[b]{2}{*}{ DMU } & \multicolumn{5}{|c|}{ Relaxation variable } & \multirow{2}{*}{$\begin{array}{c}\text { Residual variable } \\
\mathrm{S}_{1}{ }^{+0}\end{array}$} & \multirow[b]{2}{*}{$\theta \circ$} & \multirow{2}{*}{$\begin{array}{c}\text { DEA } \\
\text { effectiveness }\end{array}$} \\
\hline & $\mathbf{S}_{1}^{-0}$ & $\mathbf{S}_{2}{ }^{-0}$ & $\mathbf{S}_{3}{ }^{-0}$ & $\mathrm{~S}_{4}^{-0}$ & $\mathrm{~S}_{5}{ }^{-0}$ & & & \\
\hline $\mathrm{DMU}_{1}$ & 0.000 & 0.000 & 0.000 & o. 000 & 0.000 & 0.000 & 1. 000 & effective \\
\hline $\mathrm{DMU}_{2}$ & 58.273 & 0.000 & 111.212 & 30. 087 & 285.818 & o. 000 & o. 776 & invalid \\
\hline $\mathrm{DMU}_{3}$ & o. 000 & o. 000 & 99.098 & 24. 429 & 138.575 & o. 000 & o. 388 & invalid \\
\hline $\mathrm{DMU}_{4}$ & 0.000 & 51. 248 & 53. 998 & o. 000 & 185. 655 & o. 000 & o. 748 & invalid \\
\hline DMU5 & o. 000 & 59. 781 & 37. 099 & 0.000 & 261.569 & 0.000 & o. 990 & invalid \\
\hline $\mathrm{DMU}_{6}$ & o. 000 & o. 000 & o & o. 000 & 0.000 & o. 000 & 1. 000 & effective \\
\hline DMU7 & o. 000 & 30. 921 & 199. 15 & 34. 190 & 589. 428 & o. 000 & o. 589 & invalid \\
\hline DMU $_{s}$ & 0.000 & 165. 592 & 433. 738 & 68. 703 & 1124. 269 & o. 000 & o. 911 & invalid \\
\hline DMU9 & o. 000 & 41. 054 & 354. 208 & 110. 751 & 842. 797 & o. 000 & o. 630 & invalid \\
\hline DMU $_{10}$ & o. 000 & 238. 599 & 643. 544 & 105. 220 & 1385. 027 & o. 000 & o. 646 & invalid \\
\hline $\mathrm{DMU}_{11}$ & o. 000 & 239. 771 & 679. 526 & 130. 144 & 921.201 & o. 000 & o. 541 & invalid \\
\hline DMU $_{12}$ & o. 000 & 126. 782 & 1548.632 & 255. 913 & 2376. 123 & o. 000 & o. 760 & invalid \\
\hline $\operatorname{DMU}_{13}$ & o. 000 & o. 000 & 828. 383 & 342.112 & 1811.589 & 0.000 & 0.634 & invalid \\
\hline DMU $_{14}$ & 0.000 & o. 000 & 972.494 & 348.027 & 2007.089 & o. 000 & 0.622 & invalid \\
\hline
\end{tabular}

Among them, $s_{1}^{-0}$ is number of corresponding companies, $s_{2}^{-0}$ is number of corresponding products, $s_{3}^{-0}$ is corresponding physical output, $s_{4}^{-0}$ is Corresponding to annual sales, $s_{5}^{-0}$ is Corresponding production area, $s_{1}^{+0}$ is corresponding export amount

\subsubsection{DEA efficiency value analysis}

Technical efficiency is reflected in the level of output maximization under the established conditions, and technical efficiency can be further decomposed into pure technical efficiency and scale efficiency. Through the CR model, the DMU efficiency changes of green food exports in Heilongjiang Province were obtained. The results are shown in Table 2. 
Table 2. Efficiency value of green food export development in Heilongjiang Province from 2001 to 2014

\begin{tabular}{|c|c|c|c|c|}
\hline yeaxs & $\begin{array}{l}\text { Comprehensive } \\
\text { efficiency }\end{array}$ & $\begin{array}{l}\text { Puxe technical } \\
\text { efficiency }\end{array}$ & $\begin{array}{l}\text { Scale } \\
\text { efticiency }\end{array}$ & $\begin{array}{l}\text { Scale } \\
\text { benefit }\end{array}$ \\
\hline 2001 & 1.000 & 1.000 & 1.000 & - \\
\hline 2002 & o. 776 & a. 776 & 1. 000 & $\ldots$ \\
\hline 2003 & o. 388 & o. 472 & 0.822 & ixs \\
\hline 2005 & o. 990 & 1.000 & 0.990 & $d x=s$ \\
\hline 2006 & 1. 000 & 1.000 & 1.000 & 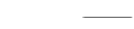 \\
\hline 2007 & o. 589 & o. 613 & o. 960 & $i_{x}=\mathrm{s}$ \\
\hline 2008 & 0.911 & 1. 000 & 0.911 & $d x=5$ \\
\hline 2011 & o. 511 & 0.544 & o. 994 & $i x=$ \\
\hline 2012 & o. 760 & 0.762 & 0.997 & ix $x$ \\
\hline 2013 & o. 634 & 0.649 & 0.997 & $d x=s$ \\
\hline 2014 & o. 622 & 0.649 & 0.958 & $d_{x}=$ \\
\hline
\end{tabular}

Note: Irs-increasing returns to scale; drs- Diminishing returns on scale;”-“- Scale returns remain unchanged

It can be seen from Table 2 that the DEA of green food exports in Heilongjiang Province is generally inefficient and has some fluctuations. Among the 14 DMUs that were examined for green food exports, except for the DEA efficiency value of 1 in 2004, and $\boldsymbol{s}^{-}=\mathbf{0}, \boldsymbol{s}^{+}=\mathbf{0}$, the DEA efficiency values of the DMUs in all other periods were all less than 1 , indicating that the output obtained under the input did not reach Maximum value. Further analysis shows that the efficiency of green food export development in Heilongjiang Province depends not only on the scale of input factors, but also on the allocation of input factors and factors utilization.

\subsubsection{Scale return analysis}

The scale of income measurement reflects the quantitative reflection of the increase in input and output. The scale efficiency of green food exports in Heilongjiang Province has changed significantly in different periods. Since 2001, the scale efficiency value has decreased (except in 2004), and at the same time in 2005 The increase in scale returns (except for 2006) and the trend of scale efficiency reduction fully demonstrate that the scale efficiency of green food exports has a reverse effect on overall efficiency, and does not achieve resource allocation efficiency and resource utilization, resulting in the green food industries' scale is not economical in Heilongjiang Province. Therefore, the improvement of the development level and efficiency of green food export in Heilongjiang Province is not to blindly expand the input of resource elements, but to maintain the rational resource input scale, focus on improving the efficiency of pure technology and strengthen resource allocation, transform the mode of industrial development, and give full play to industrial technology. Advantages, export development efficiency is likely to further increase.

\section{Conclusion}

Through the DEA method to analyze and evaluate the development of green food exports in Heilongjiang Province from 2001 to 2014, reveal the changes in the development efficiency and scale of green food export development, and point out the industrial structure adjustment and improvement direction according to the projection analysis, and draw the following main conclusions: the comprehensive efficiency of green food export development in Heilongjiang Province is low and in a downward trend. The direct cause is mainly the low efficiency of pure technology. The root cause is that green food in Heilongjiang Province ignores market demand and international market development, and industrial development excessively pursues scale expansion. Neglect the "growth, no development" industry development mode of internal quality improvement. The development of green food export development in Heilongjiang Province is imperative to the development mode of "intensive, export-oriented and profitable” industries.

\section{Acknowledgment}

This research was supported by Philosophy and Social Sciences Planning Project in Heilongjiang 
(No.16JYB14); Humanities and Social Sciences Planning Project of Heilongjiang Education Department (No.12542060); and Ph.D. research project of Harbin Universe of Commerce (No. 14RW14).

\section{References}

[1] SONG De-jun, ZHOU Wei,MA Shi-peng. Analysis and Evaluation of the Influence of International Competitiveness of Green Food Industry in Heilongjiang Province[J].Journal of Lanzhou University of Commerce,2013(5): 16-23.

[2] Yu Liping, Yan Wei. Research on China Export Efficiency Measurement Based on DEA[J].Science and Technology and Management,2013, 15(6): 80-87.

[3] Li Peng,Zeng Guang. Evaluation and Analysis of the Efficiency of China's Agricultural and Non-staple Food Processing Industry_-Based on the Measurement of Three-stage DEA Model[J].Journal of the Economics and Industry,2014(4): 79-88

[4] Coelli T J. A Guide to DEAP Version 2.1: a data envelopment analysis pronram[R]. CEPA working paper, 1996

[5] John Adams. Industrial clusters and regional economic development in China: the case of "green food”[J].Journal of Chinese Entrepre-neurship, 2009, 1(3): 279-294 